\title{
13. The Play's the Thing: Towards an Aesthetics of Engagement. Carving Our Futures from a Tombstone
}

\author{
Tim Prentki \\ doi.org/10.3280/oa-637-13
}

\section{Introduction}

\author{
The play's the thing \\ Wherein I'll catch the conscience of the king. \\ [Hamlet, II.2.600-601]
}

Hamlet commissions a performance of The Mousetrap in the expectation that Claudius will respond in a way which will confirm his guilt in the murder of Hamlet's father. He believes in the power of a simulated action (like the reenactment of a crime scene) to engage an audience member so profoundly as to alter their behaviour. When the king exits hurriedly from the auditorium in a disturbed state, Hamlet thinks his plan has worked. However, it remains unclear whether Claudius is the possessor of a conscience that can be "caught". He has thus far successfully separated his action from his public performance as king in the manner of many contemporary politicians.

This paper is an exploration of the possibilities of applied theatre for imagining, and perhaps taking the first, tentative steps towards achieving, a different future from the one which seems to be beckoning as we perform our nationalist, neoliberal dances around the vortex of planetary destruction. I'm taking the opportunity so kindly afforded me by the Organising Committee of Performing the Social to reflect upon my career as a Theatre for Development pedagogue: what I've learnt and what I've still to learn. At the heart of this reflection lurks an inextinguishable hope that the human species will "forsake its foolish ways" in favour of a search for a path which more truly traces out a potential for equitable, non-exploitative relations in pursuit of social justice. Allied to this hope is the contention that theatre is an essential means for achieving this aspiration.

\section{Dicing with Humanity}

DICE (Drama Improves Lisbon Key Competences in Education) was an international EU-supported project. In addition to other educational aims, this two-year project was a cross-cultural research study investigating the effects of educational theatre and drama on five of the 
eight Lisbon Key Competences [:] communication in the mother tongue; learning to learn; interpersonal, intercultural and social competences, civic competence; entrepreneurship; cultural expression. Furthermore, we believe that there is a competence not mentioned among the Key Competences, which is the universal competence of what it is to be human (Cziboly, 2010).

The sixth face of the DICE asserts not only that being human is enabled by engaging in theatre but also that this enabling is universal. Whatever the context, social, geographical, cultural, young people are more likely to develop their human potential if they are given the opportunity to engage in theatre processes. This is the startlingly ambitious conclusion of the study, the implications of which, if taken seriously by those involved in education the world over, require an entire rethinking of what today passes for education across the globe. The further implication is that a failure to act on this conclusion is, in effect, a denial of what it is to be human. In other words, our present educational systems are not the means by which we achieve our potential but rather barriers to that achievement. Perhaps it is not surprising that there is very little evidence that this conclusion has been acted upon. In a speech given at Madison Park High School, Boston, on June $23^{\text {rd }} 1990$ Nelson Mandela said that «education is the most powerful weapon which we can use in order to prepare our youth for their role as leaders of tomorrow» ${ }^{60}$. Maybe this is why politicians and educational policy-makers are so concerned to keep this weapon out of the hands of the young people who have a vested interest in changing the world. The kind of education made possible by applied theatre will produce changes that would result in an alternative future to the suicidal one towards which we are currently stumbling.

The status quo is not the result of ignorance but of the wilful intention of nations, democratic or totalitarian, to keep the weapon out of the hands of tomorrow's young change-makers. Article 13 of the 1989 UN Convention on the Rights of the Child states that:

The child shall have the right to freedom of expression; this right shall include freedom to seek, receive and impart information and ideas of all kinds, regardless of frontiers, either orally, in writing or in print, in the form of art, or through any other media of the child's choice (United Nations Convention on the Rights of the Child, 1989).

${ }^{60} \mathrm{https}: / /$ www.youtube.com/watch?v=b66c6OkMZGw\&ab_channel=GBHNews 
All nations with the exception of the USA have subscribed to the CRC. Our young people have a right to theatre; a right to a process that supports the development of their potential as humans.

In those countries where the responsibility to educate the population is honoured (and there are many where it is not), the curriculum follows what Ken Robinson (Robinson, 2015) has called "the industrial model" where young people are treated like the products of a production-line, subjected to identical processing according to age rather than aptitude, interest or capability. It is, indeed, a model deriving from the Industrial Revolution when the "captains of industry" realised that for the work-force to be efficient and, hence, profits maximised, it was necessary to educate it to a minimum standard. Today we are still creating educational systems according to this principle and therefore training young people for a world that either no longer exists or is writing its own suicide note, all under the pretence of "employability". Knowing this, we, all of us, are reneging on our responsibility to the generations who succeed us, if we do not offer a curriculum constructed with the central pillars of creativity and criticality. In the words of my old colleague David Pammenter:

If we truly believe in the humanising power of theatre, then as theatre artists we must, by extension, be concerned with concrete issues of justice, rights and responsibilities. This holds true whether we are creating the theatre, presenting it, observing it or participating in it. Our theatre must be about the amplification of voices and the revelation of experiences that cause us to question our perceptions, assumptions, beliefs and actions (Jackson and Vine, 2013, p. 84).

\section{Developing the World, Applying Theatre}

In his inaugural address to the nation on January $20^{\text {th }} 1949$, Harry Truman coined the term "underdeveloped" to describe most of the countries comprising the southern hemisphere. Henceforth the "developed" North has made interventions, both military and "soft", into the affairs of underdeveloped nations in order to expose them to the benefits of development. Thus development became the new colonialism with transnational corporations, supported by global financial institutions such as the World Bank and the IMF, performing the roles previously assigned to invading armies. Through the notorious "conditionalities", the repayment of loans became the mechanism by which most of the world's countries had to conform to the template of economic and social development imposed by the Washington Consensus. Rather than meaning the fulfilment of human 
potential, to be developed meant to be like "us" - "us" being principally the United States and its Western allies:

The mental space in which people dream and act is largely occupied today by Western imagery. The vast furrows of cultural monoculture left behind are, as in all monocultures, both barren and dangerous. They have eliminated the innumerable varieties of being human and have turned the world into a place deprived of adventure and surprise: the "other" has vanished with development. Moreover, the spreading monoculture has eroded viable alternatives to the industrial, growth-oriented society and dangerously crippled humankind's capacity to meet an increasingly different future with creative responses (Sachs, 1992, p. 4).

The desire for everyone else to be like us can easily be converted in the mouth of a demagogue to crude racism. The casualties have already been many of the, now lost, languages of the world, together with the knowledge and ideas that were held within their discourses. Today Japanese architects visit Machu Picchu to try to discover the secrets of the Incas earthquake-proof construction methods because the Conquistadores were not interested in finding out before they massacred them. Like the European settlers in North America and the Zionist immigrants to Palestine in 1948 («a land without people for a people without a land»), if the inhabitants did not look and behave like us, they could not be classified as humans. These are extreme examples but similar tropes are played out more subtly all the time.

Many applied theatre and theatre for development projects have the undeclared aim of getting participants to conform to another's notion of how to live. "Social inclusion" has a cosy feel to it. Nothing is worse than feeling left out. However, it can mask a coercive intention if those whom we are trying to include have freely opted for exclusion on the grounds that they do not wish to be like us. Much of applied theatre arises from a neoliberal deficiency model of society where the participants - prisoners, the homeless, users of mental health services, the disabled, etc. - lack something that "normal" people possess. By giving these unfortunates a dose of theatre; by applying theatre like a bandage to the open wounds of their deficient social conditions we may be helping them back into the orbit of a neoliberal social consciousness. By declaring an aim of social inclusion we shall also increase the prospect of getting funding for projects which will domesticate recalcitrant and disruptive sections of society, especially if we can demonstrate how our intended outcomes will be measured in quantitative data.

Jamil Ahmed's Bangladeshi experience can be replicated throughout "underdeveloped" communities: 
It is a subtle form of manipulation, in that local NGOs are apparently not forced or even dictated to but are simply not funded unless they are willing to follow the normalising framework set by the donors. More often than not local NGOs simply function as mercenaries who are first normalised by accepting donor funding and then they go out to normalize the "community" and "help" its members to lead docile lives (Ahmed, 2007, pp. 209-210).

However, the confidence with which President Truman announced a brave new world of development with the United States as global saviour has long since vanished under the rubble of man-made conflicts of power, money and nationalism, or been burnt to death or drowned by man-made global warming. As Naomi Klein writes in her aptly titled This Changes Everything:

Free market ideology has been discredited by decades of deepening inequality and corruption, stripping it of much of its persuasive power (if not yet its political and economic power). And the various forms of magical thinking that have diverted precious energy - from blind faith in technological miracles to the worship of benevolent billionaires - are also fast losing their grip (Klein, 2014, p. 465).

The very notion of conventional development is, in these circumstances, discredited. If the concept is to be of use in our world, it will have to transform itself into a bottom-up, grassroots process which takes effective account of the various functions of culture in relation to human behaviour. In 2004 Helen Gould and Mary Marsh wrote a report for the UK Department for International Development, Culture: Hidden Development which exposed the lack of consideration given to cultural factors in development:

... culture is invisible because cultural plurality is inconvenient for development. It is far easier for the machinery of development to function in a world where cultures do not get in the way of political and economic progress: where communities share a set of universal values which make them respond uniformly to change. Furthermore, culture is part of the landscape of human rights which makes it doubly uncomfortable - not only are people diverse in language, thought, belief and identity, but it is part of their inalienable rights to remain so (Gould and Marsh, 2004, p. 22).

\section{Back to the Future}

This matter of culture lies at the core of applied theatre, a discipline that is located at the crossroads of many others: anthropology, history, human geography, performing arts, psychology, sociology and, more recently, 
neuroscience. Darko Lukic speaks of applied theatre as existing «in between cultural production and social activism» (2021, p. 82) while for Jan CohenCruz «applied theater, between culture and art, draws on expressive means to uplift what is special about groups of people often in ways that connect them to everyone else» $(2021$, p. 241). I'm speaking here of culture in its anthropological sense (how we make meaning of our lives) and in its aesthetic sense (how we make art of our lives). The unique function of applied theatre is to weave a dialectic into the fabric of culture whereby it simultaneously puts art into the meaning of daily living and invests artmaking with meanings drawn from daily life. This integrative process is actualised through a theatre aesthetic that stimulates the imagination to conceive alternative futures that grow out of lived experience. The creative tension between imagination and reality which stretches like a spinal cord down the skeleton of applied theatre is recast in relation to culture by Arjun Appadurai thus:

culture is a dialogue between aspirations and sedimented traditions. And in our commendable zeal for the latter at the cost of the former, we have allowed unnecessary, harmful and artificial opposition to emerge between culture and development (quoted in Gould and Marsh, 2004, p. 17).

This opposition is expressed when theatre for development projects separate the art from non-theatrical outcomes; when we engage in theatre for a predetermined result such as reducing re-offending rates among prisoners or instances of teenage pregnancy among socially deprived young women. In these cases a notion of what it means to live well has been imposed by an outside agency and theatre is just a delivery mechanism for that notion. However, where the focus falls upon the theatre engagement, the affects and effects upon participants, and hence the meanings that may emerge are unpredictable, potentially rich and containing the possibility of selfactualisation.

The DICE project spoke of «what it is to be human». Philosophy down the ages has offered many definitions but a frequent common denominator has been the expression of the seemingly contradictory impulse to free will on the one hand and the recognition of the constraints into which we are born on the other. Karl Marx offered his analysis in his essay The Eighteenth Brumaire of Louis Bonaparte:

Men make their own history, but they do not make it just as they please; they do not make it under circumstances chosen by themselves, but under circumstances directly encountered, given and transmitted from the past. The tradition of all the dead generations weighs like a nightmare 
on the brain of the living. And just when they seem engaged in revolutionising themselves and things, in creating something that has never yet existed, precisely in such periods of revolutionary crisis they anxiously conjure up the spirits of the past to their service and borrow from them names, battle cries and costumes in order to present the new scene of world history in this time-honoured disguise and this borrowed language (McLellan, 1980, p. 63).

Marx reminds us that control of the meaning of the past is crucial in determining how we relate to that past. In our digital, so-called "post-truth" world it is easy to fall victim to versions of the past that serve the current interests of those who would manipulate our present. The ghosts of empire and world war clank their chains in rhythm to the Brexit chant of «take back control» while the flaming crosses of the Ku Klux Klan illuminate demands to «make America great again». The jack-boots of fascism echo to cries of «Prima gli Italiani» and the perennial appeal to «il buonsenso». A fundamental element of community theatre is the creation of space in which participants explore their experiences of cultural identity on their own terms, unmediated by the discourses of neoliberalism, nationalism or populism. Part of that exploration is a consideration of the past that shapes them. What do they bring into the theatrical space from which any imagined reality might emerge? Notwithstanding Peter Brook's famous phrase «the Empty Space», no space is empty but always contains the meanings projected onto it which are themselves the product of past physical, psychological and ideological encounters.

I witnessed one of the more dramatic examples of this phenomenon back in the 1990s when I was supervising a masters project taking place on a Cree reserve in Alberta, Canada. The two masters students had been working for three months with two terminally ill elders (women in their fifties) who lived in a hospice on the reserve. They were persuaded to create a performance for family and friends involving shadow-puppets and music. One of the women was confined to a wheelchair so possibilities for physical performance were limited. Much of the content of the performance revolved around the women's childhood memories which involved being told stories by their grandparents of the days before the arrival of the Europeans in large numbers. They were tales of the old ways, packed with indigenous knowledge and wisdom. What struck me most at the time and has stayed with me ever since was the polarised responses to the show which emerged in the conversations that immediately followed it. The children of the performers together with others of the same generation were polite and respectful but did not engage with the quaint, old-fashioned tales. The grandchildren by contrast were enthralled, and infuriated that these understandings had been 
kept from them. They demanded to know more and to be put in touch with the well-springs of this existence. It was as if they had just uncovered a part of their identities previously hidden from them. The breaking down of a wall of cultural alienation had released them into newly imagined places of selfdiscovery.

The experience chimes in with Paulo Freire's view of education as a process which can lead to transformation only if grounded in the historical realities of the subjects:

Problem-posing education bases itself on creativity and stimulates true reflection and action upon reality, thereby responding to the vocation of persons as beings who are authentic only when engaged in inquiry and creative transformation. In sum, banking theory and practice, as immobilizing and fixating forces, fail to acknowledge men and women as historical beings: problem-posing theory and practice take the people's historicity as their starting point (Freire, [1970] 2005, p. 84).

Freire, like Marx, identifies ideology as the source of a false consciousness that alienates people from the roots of their own being and prevents them from taking an active hold on their self-development. The antidote to ideology is the grounding of each person's participation in lived experience; that is in the historical moment of their being. In the words of the Control Chorus at the end of Bertolt Brecht's Lehrstück The Measures Taken: «Taught only by reality can/Reality be changed» (Brecht, 1977, p. 34).

\section{Danger: Live Wire}

The underlying concept that links all the various branches of applied theatre - TIE, TfD, Community Theatre, etc. - is change. We devote our professional lives as practitioners and academics to this activity because we believe in the possibility and necessity for change. This is why I take Brecht to be the founder of the discipline. In his Katzgraben Notes written in 1953 he reflects on the fundamentals of his theatre:

I wanted to apply to the theatre the principle that it is important not only to interpret the world, but to change it. The changes, whether big or small, that ensued from this intention - an intention which I myself only gradually came to recognize - were only ever changes within the framework of theatre (Kuhn, Giles and Silberman, 2014, p. 251).

The basis of our art is change understood as both social change to address manifest injustices and inequalities (changing the world), and personal change because each of us is a member of an evolving species, constantly in 
a state of flux. We do not choose change; change chooses us. Recent discoveries in the neuroscience of the human brain confirm not only that we are wired for change in that our neural pathways are stimulated by responding to the signals given out by others, «altercentric participation» (Bråten, 2007, p. 2), but also that faults and short-circuits can be repaired through engagement in dialogue and interaction.

Vittorio Gallese asserts in his Embodied Simulation Theory that the discovery of mirror neurons means that our behaviour and emotional states resemble the brain activity of an audience observing theatrical action:

... the fundamental mechanism that allows us a direct experiential grasp of the mind of others is not conceptual reasoning but direct simulation of the observed events through the mirror mechanism (Gallese, Keysers and Rizzolatti, 2004, p. 397).

In other words our brains operate through the theatrical modes of actor, character and audience. When Stein Braten describes the stages through which recognition of the social environment occurs, he provides a neurological parallel to the process of a drama workshop:

The shifting between dialogical competence and consciousness manifests itself in the intersubjective attunement at various levels - from confluence of affect at the primary level to advanced self-other simulation and constructions at a more advanced level involving internal selfcreative and dialogical circles of complementary self-other perspectives (Bråten, 2007, p. 23).

We invite workshop participants to bring their life experiences into dialogue with those of others so that perspectives are altered and changes become possible. At that point imagination is drawn upon in order to rehearse a future action that grows from these changes. The neurological circuits are lit up by input of energy deriving from the stimulus of collective creation.

Drama therapist Salvo Pitruzzella has worked for many years on the borders of therapy and intervention or, as I might express it in this discourse, repair and change. For him the theatre process offers the opportunity for the patient (the one who suffers) to be transformed into the agent (the one who proposes an action):

The boundaries between the actor and the audience, as well as the distance between the actor and its role, become flexible and permeable and sometimes they vanish entirely. Each of us is actor, audience and character at the same time, and the narrations become scenarios for 
improvising in a relentless process of creation and representation (Pitruzzella, 2017, p. 106).

The concept of distance is significant and explains why Pitruzzella has used Brecht a lot in his work. I have observed in my own practice that when someone performs her own story, the process of recollection creates a space between the person at the moment the event occurred (the character) and the person in the present of the performance (the actor). Far from robbing the event of its original emotion, this process preserves that emotion while enabling its expression to be channelled in the direction of a social consequence. Long before advances in neuroscience, Brecht's understanding of theatre allowed him to grasp the essential dialectic between empathy and representation which Pitruzzella has transposed to the territory of dramatherapy. Consequently, his version of therapy is not the conventional one which supports the neoliberal deficiency model whereby the patient is brought back into the fold of social inclusion through a process of domestication, but rather a notion of therapy as change whereby renewed self-possession leads to both personal and social intervention to enable a different future.

A different future at both micro and macro levels is a matter of urgency given the state of the planet. In his book Collapse: How Societies Choose to Fail or Survive biologist Jared Diamond comes to this conclusion:

Two types of choices seem to me to have been crucial in tipping their outcomes towards success or failure: long-term planning, and willingness to reconsider core values. On reflection, we can also recognize the crucial role of these same two choices for outcomes of our individual lives (Diamond, 2005, p. 522).

Applied theatre is a means of reconsidering "core values" because it creates an arena, a safe space if you will, where the unsayable can be said and the unthinkable thought. Here we can rehearse futures in which such fundamentals as over-population and unfettered consumption can be challenged.

\section{Wired for Hope}

Although we are equipped with the neuroplasticity required to remake ourselves according to how we wish to live rather than according to the economic and ideological dictates of others, there are, as "Bifo" Berardi has pointed out, powerful obstacles in our path: 
Reviving the intensity of bodily sensibility, and disentangling the potency of the general intellect from the techno-economic apparatus are the cultural and political tasks of the future, and they are narrowly linked (Berardi, 2015, p. 295).

Adopting the concept of neuroplasticity as the means by which new conjunctions are forged between the world and the mind, he speaks of «neural evolution» (ibid., p. 257) through epigenetic recoding as the only means of finding our way out of the semiotic model of capitalism that is currently our only «grid of perception and interaction» (ibid., p. 261). Today that way out is strewn with the rubbish and pot-holes made by demagogues who would happily carve our futures from tombstones to secure their own power over us: Trump, Putin, Bolsonaro, Duterte, Salvini, etc. The phenomenon of creating enemies is not new, as Theodore Zeldin points out:

fabricating enemies is one of the oldest and busiest of human industries, and the raw material may be nothing more than hurt pride and anger, gradually hardening until the manufacturers become prisoners of their hatred. When they do not choose their enemies for themselves, others do so on their behalf (Zeldin, 1998, p. 218).

The antidote to this broadcast and social media induced false consciousness is an educational process, accessible to all, that is grounded in the lived experience of young people and of all those with whom we engage through an applied theatre approach. The right to make our own meanings rather than succumb to interpretations of reality fostered by corporate giants is fundamental to our processes. Berardi again shows how applied theatre methods are at odds with the prevailing styles of corporate communication:

In the sphere of the digital economy, the faster information circulates, the faster value is accumulated. But meaning slows down this process, since meaning needs time to be produced and to be elaborated and understood. So the acceleration of information flow implies the elimination of meaning (Berardi, 2015, p. 162).

The uncovering of meaning lies at the heart of our two-way processes. We engage with theatre drawn from the raw material of our lives in order to benefit from a distance that enables us to see better how we relate to the wider world and the act of engagement itself lends meaning to our existence. The purposelessness and alienation that accompanies so many lives when people feel they are unable to exert any control over their circumstances, can be combatted, albeit temporarily, by framing life in art that opens up the possibility for change. We may only see enough to see how little we can see 
but that "little" can offer a kernel of meaning that sets us off on a different path. There may be no single meaning to life but as self-conscious humans each of us can enhance the quality of our existence by discovering a meaning and that process of discovery is greatly assisted by the interaction between life and art, reality and imagination.

Young people in particular are prone to frame their expectations in terms of social justice as their most recent manifestation, the Extinction Rebellion movement, demonstrates. This is why it is vital to honour their right to engage in theatre; to roll the dice for their turn to create. As my former colleague Michael Etherton wrote:

What constantly amazes us adults is the quality of the drama the young people create in the process of defining the infringement of their rights. In country after country, in culture after culture, children and young people have a beautiful sense of dramatic improvisation. Young people's art in all kinds of creative media, coupled with their struggle for their rights in an unfair world, stands a good chance of changing the future in ways we adults cannot now imagine (Etherton, 2006, p. 118).

When it comes to the "universal competence of what it is to be human», the play is, indeed, the thing. If not now, when? 